\title{
Single-Dose, Open-Label Study of the Differences in Pharmacokinetics of Colchicine in Subjects with Renal Impairment, Including End-Stage Renal Disease
}

\author{
Yalcin Solak • Seyyid Bilal Acikgoz • \\ Mehmet Yildirim
}

Published online: 19 December 2014

(c) Springer International Publishing Switzerland 2014

We read the article by Wason et al. [1] with great enthusiasm. The authors conducted an elaborate study in which they investigated colchicine pharmacokinetics in subjects with different levels of kidney function. The authors administered colchicine to eight patients with end-stage renal disease (ESRD) in two periods 15 days apart. In each period, a single dose of colchicine $0.6 \mathrm{mg}$ was administered (in period 1, post-dialysis; in period 2, pre-dialysis). Interestingly, the results of the study showed similar plasma colchicine concentrations between subjects with mildly diminished renal function and haemodialysis patients. This may be due to administration of only a single dose $(0.6 \mathrm{mg})$ of colchicine to the study groups. Treatmentemergent adverse events were observed in four of the eight subjects with ESRD. These were diarrhoea and headache in one subject with ESRD. The authors also reported no laboratory abnormalities attributable to colchicine in these subjects, though what tests were implied was not clear.

Although not cited in the current study by Wason and colleagues, the largest study in the current literature looking at the safety of colchicine in patients with ESRD undergoing haemodialysis was ours [2]. We evaluated the clinical and laboratory safety of colchicine in a case-control study in which 22 maintenance haemodialysis patients, along with 20 healthy control subjects, were recruited. Four of the 22 patients were using colchicine $0.5 \mathrm{mg} /$ day, four patients were using $1.5 \mathrm{mg} /$ day and 14 patients were using

Y. Solak $(\bowtie)$

Nephrology Division, Sakarya University Research and Training

Hospital, Adapazarı, Sakarya, Turkey

e-mail: yalcinsolakmd@gmail.com

S. B. Acikgoz · M. Yildirim

Department of Internal Medicine, School of Medicine, Sakarya

University, Adapazarı, Sakarya, Turkey
$1 \mathrm{mg} /$ day. The mean duration of colchicine use was $8.9 \pm 8.2$ years. There was no difference between the groups in terms of myoneuropathic signs and symptoms and blood counts, except for the white blood cell count, which was significantly higher in patients on colchicine. Serum creatine kinase levels $(56.3 \pm 39.5$ and $52.1 \pm 36.1 \mathrm{U} / \mathrm{L}$ in the colchicine and control groups, respectively; $P=0.72$ ) and myoglobin levels $(191.4 \pm 108.8$ and $214.6 \pm 83.5$ $\mathrm{ng} / \mathrm{mL}$ in the colchicine and control groups, respectively; $P=0.44)$ did not differ between the groups. Significant polypharmacy was also present for the subjects who were on colchicine treatment. Despite use of higher doses for long periods and the presence of polypharmacy, colchicine seemed rather safe for the haemodialysis patients. However, because of the study design, bias favouring selection of patients who tolerated colchicine well could not be excluded from our results.

Considering the growing population of patients with gout and familial Mediterranean fever who require dialysis, further studies are needed to extend the findings of the aforementioned studies.

Conflict of interest and disclosure statement No sources of funding were used in the preparation of this manuscript. The authors have no conflicts of interest that are relevant to the content of this letter.

\section{References}

1. Wason S, Mount D, Faulkner R. Single-dose, open-label study of the differences in pharmacokinetics of colchicine in subjects with renal impairment, including end-stage renal disease. Clin Drug Investig. 2014;34(12):845-55.

2. Solak Y, Atalay H, Biyik Z, Alibasic H, Gaipov A, Guney F, et al. Colchicine toxicity in end-stage renal disease patients: a casecontrol study. Am J Ther. 2014;21(6):e189-e195. 